\title{
SM Otolaryngology Anterior Chest Wall Abscess Secondary to Odontogenic Infection: A Case Report
}

\author{
Khemanand Maharaj ${ }^{\star}$ and Steven Liggins* \\ Department of Oral and Maxillofacial Surgery, Mid-Essex Hospital Trust, United Kingdom
}

\section{Article Information}

Received date: Aug 07, 2017

Accepted date: Aug 30, 2017

Published date: Sep 04, 2017

${ }^{*}$ Corresponding author(s)

Khemanand Maharaj, Clinical Fellow, Oral and Maxillofacial Surgery department, Mid-Essex Hospital Trust, Chelmsford, United Kingdom,

Tel: +447958156125;

Email: khemanand.maharaj@gmail.com

Steven Liggins, Consultant, Oral and Maxillofacial Surgery department, MidEssex Hospital Trust, Chelmsford, United Kingdom, Tel: +4407824612847;

Email: imagemedical@btinternet.com

Distributed under Creative Commons CC-BY 4.0

Keywords Odontogenic; Infection; Neck abscess

Article DOI 10.36876/smotol.1011

\section{OPEN ACCESS}

ISSN: 2574-2418

\section{Abstract}

Objective: Management of neck space infection with subsequent supra/sub-platysmal spread of infection involving the superficial fascia of the anterior chest wall.

Methods: A 23 year old male presented to the OMFS department at Broomfield hospital with a history of right neck swelling and trismus secondary to carious third molar and second molar teeth. He was diagnosed with a right submandibular space dental abscess, placed on empirical antimicrobials [Co-Amoxiclav ${ }^{\circledR}$ and Metronidazole $\circledast$ ] and underwent incision and drainage plus extraction of carious teeth involved. He subsequently developed an area of erythema over his right anterior chest wall, which rapidly progressed to form an area of fluctuant swelling and tenderness suggestive of an abscess. A Computer Tomography scan was requested which showed a large supraclavicular and superficial anterior chest wall collection suggestive of an abscess.

Results: This patient underwent successful incision and drainage of anterior chest wall abscess and placed on appropriate antimicrobials.

Conclusion: Neck space infections must be treated aggressively with intent to adequately drain all areas of collections to prevent spread of infection into the mediastinum and in this case, unusual spread to the anterior chest wall.

\section{Introduction}

The most common cause of infections in the head and neck region are odontogenic in origin $[1,2]$. These infections can be managed adequately with removal of the affected tooth and antibiotic implementation. Occasionally these infections can spread through fascial spaces, which are largely dependent on the location of the tooth and anatomy of the head and neck. Space infections are treated surgically by incision, drainage of pus, and removal of necrotic tissue [3]. Inappropriate surgical management of space infections of the head and neck can result in progression to life threatening complications. Such complications include sepsis, mediastinitis, Lemierre's syndrome, necrotizing fasciitis, empyema aspiration pneumonia and brain abscesses [4-6]. Much of the literature has spoken about these complications but only one case thus far has been reported on spread of odontogenic infection to the anterior chest wall [7]. We present another unusual case of a neck space abscess extending to the anterior chest wall following surgical intervention.

\section{Case Report}

A 23 year old male presented to the Oral and maxillofacial department, Broomfield hospital complaining of pain and swelling of the right neck with associated trismus and dysphagia. He previously had pulpitis type pain from the lower right second molar and subsequently developed swelling in the right side of his neck. His medical history was no significant but socially he was homeless at that time.

Clinical Examination revealed right-sided neck swelling involving the submasseteric and buccal spaces with erythema over the right supraclavicular region. He also had trismus with limited opening up to approximately $20 \mathrm{~mm}$. Intra-orally his floor of mouth appeared normal but he did have a carious lower right second molar. Dental pan tomogram showed a carious lower right second molar and an impacted lower wisdom tooth (Figure 1). He was admitted for fluid resuscitation, empirical antibiotic infusion [Co-Amoxiclav and Metronidazole"] and listed on the emergency theatre for surgical extraction of his suspected teeth and incision and drainage of dental abscess.

Following surgical management he slowly recovered but there was an area of erythema over the right supraclavicular region extending to the right anterior chest wall. This area was of some concern as it was mildly larger compared to its distribution on admission, so intravenous antibiotic therapy was to continue. The patient subsequently requested to be discharged against medical advice due to social issues. He was discharged against medical advice, but to continue oral antibiotics and be reviewed in 2 days to monitor supra clavicular region and progression.

The patient came for review to the ward and was attended to by the on call senior house officer who recognized a very distinct swelling over the right anterior chest wall that was red, tender and 


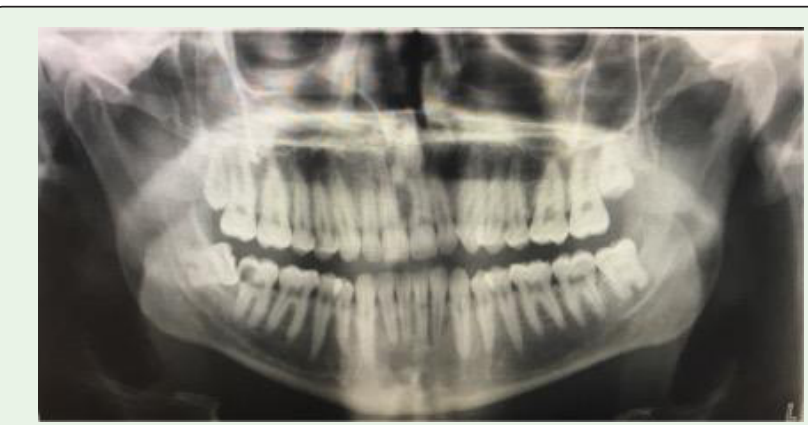

Figure 1: Dental Pantomogram showing carious LR7 and mesio-angulated impacted LR8

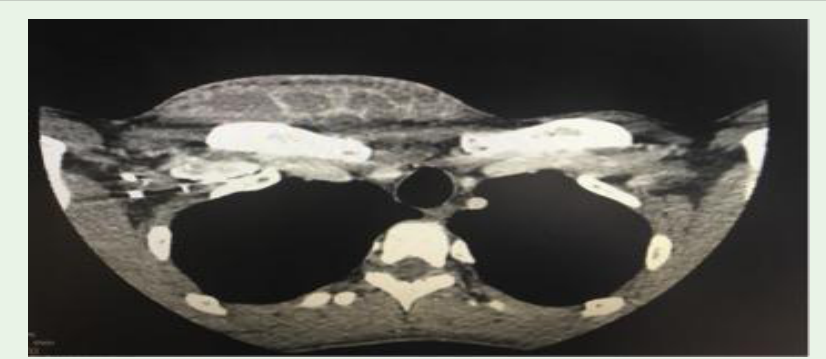

Figure 2: Axial cuts through Thorax showing loculated collection over right pectoralis major muscle.

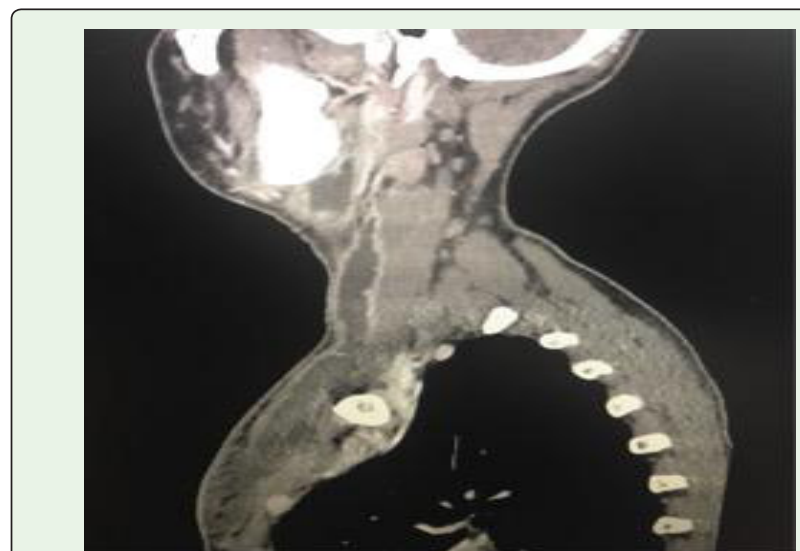

Figure 3: Sagittal cuts showing length of collection.

fluctuant. Computer tomography scans were requested to assess swelling and whether there was extension into the mediastinum.

Computer Tomography [CT] showed a huge complex abscess extending from just above the right parotid gland down the right side of the neck to extend over the right clavicle and a portion of the medial left clavicle and the sternum and anterior chest down to the level of the third anterior chest wall rib on the right (Figure 2). The collection was complex and loculated. On the cross-sectional axial images it had a maximum width of $13 \mathrm{~cm}$ and a maximum depth of 3 $\mathrm{cm}$ over the right pectoralis major muscle. On the sagittal reformats the total height of the collection was approximately $23 \mathrm{~cm}$ (Figure 3 ).

$3 \mathrm{D}$ reconstructions of the computer tomography images showed
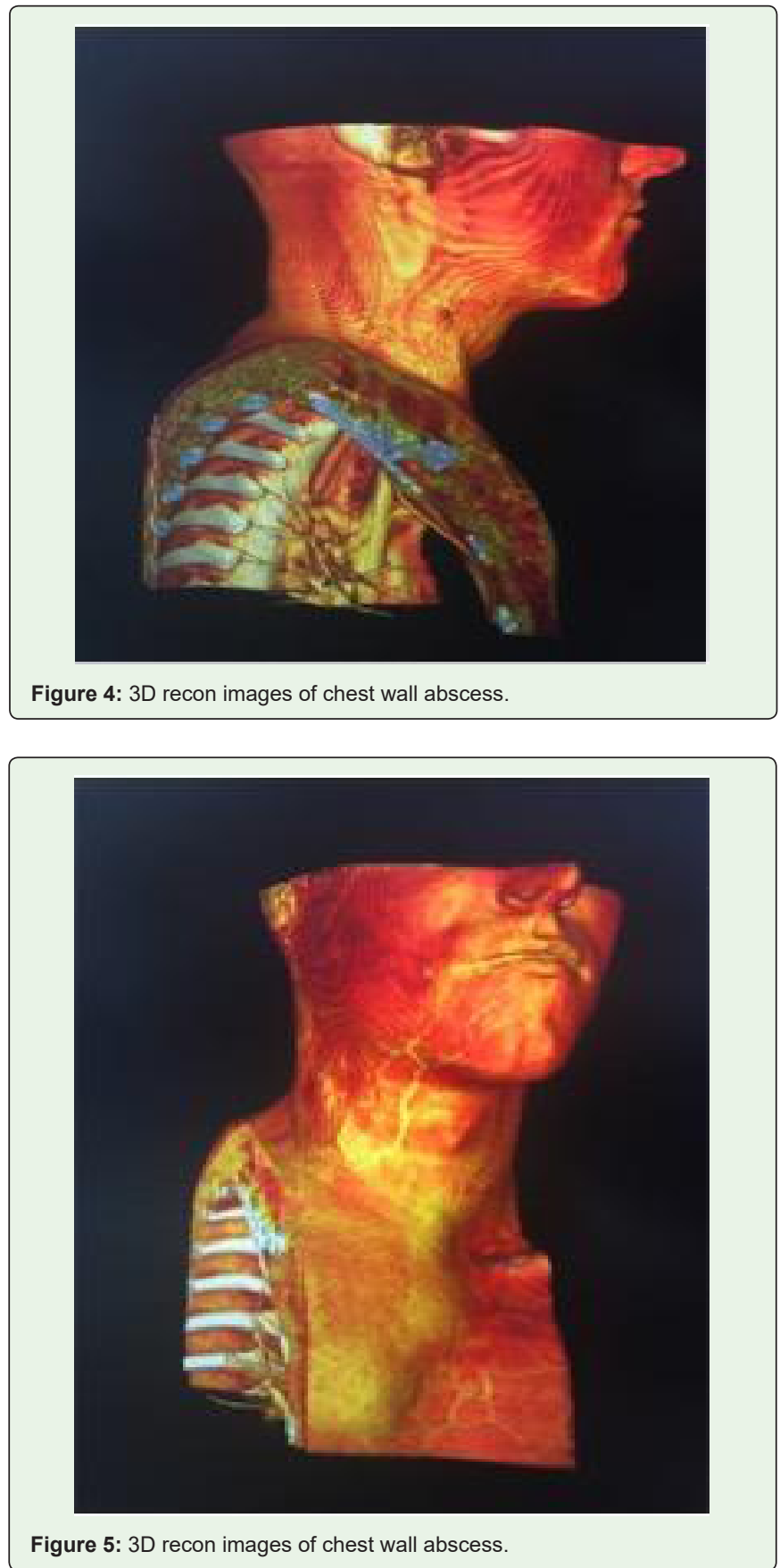

the soft tissue extent of the abscess from neck to anterior chest wall (Figures 4 and 5).

The patient was taken back to theatre for incision, drainage and washout of the neck and anterior chest wall abscess. Two large drains were placed from the neck through to the most inferior limit of the anterior chest collection to aid with drainage of residual collections. The patient was continued on intravenous antibiotics [Co-Amoxiclav and Metronidazole"] and monitoring for any further collections. The drains were removed two days post drainage and had an uneventful recovery. He was subsequently discharged with follow up at our Oral and Maxillofacial department. 


\section{Discussion}

Odontogenic infections are still of great concern despite new antibiotics and improved health care, as there is still a substantial associated morbidity, mortality and cost worldwide $[2,8]$ Usually odontogenic infections are localized and can be managed conservatively with removal of the offending tooth and antibiotics. However, they can also escape anatomical barriers and spread via haematogenous dissemination, lymphagenous dissemination and/or via facial planes into spaces within the head and neck [3].

As mentioned before, the pathways of spread is greatly determined by the position of the affected tooth and anatomical planes and spaces close by. The most common mandibular teeth associated with neck space infection are the mandibular third molars followed by the second molars [1]. The most common anatomical spaces for spread of infection from mandibular teeth are the submandibular space $[1,9,10]$ followed by buccal space $[2,11]$.

Due to the position of the roots of these teeth lying below the attachment of the mylohyoid [12] and the lingual plate being the thinnest aspect of the mandible, explains the frequent extension into the submandibular space [13]. Other potential spaces are, submasseteric space, sublingual / submental space, pterygomandibular space, and pharyngeal space.

Propagation of infection in these spaces can lead to other life threatening complications such as necrotizing fasciitis and descending mediastinitis. Necrotizing fasciitis of odontogenic origin affecting the head and neck region is a rare but life threatening clinical condition that is associated with a poor prognosis if not treated early [6] Management of necrotizing fasciitis entails surgical treatment of the necrotic tissue by debridement fasciotomy and antimicrobial therapy against the offending organism [14]. Some authors have had success with the use of negative pressure wound therapy and flow-through instillation of hypochlorous acid $[15,16]$. Other forms of therapies mentioned in the literature include intravenous immunoglobulin and hyperbaric oxygen therapy $[17,18]$.

The styloglossus muscle and neurovascular structures to the tongue pass through the buccopharyngeal gap, which can serve as a potential pathway to the lateral pharyngeal space and retropharyngeal space with subsequent descent into the mediastinum [7]. Infection along the neck can possibly extend to the axilla via the supraclavicular fossa, spread between the clavicle and the first rib to the delto-pectoral space [7] or very rarely as in this case, supraplatysmal to the anterior chest wall superior to the pectoralis major muscle.

Radiological evaluation of odontogenic infections can include a standard Orthopantomogram [OPG], CT scans, ultrasound and Magnetic Resonance Imaging [MRI]. Contrast enhanced CT scans has the advantage of clearly delineating site and size of abscesses, distinguishing them from cellulitis and determining spread to vital cavities such as the mediastinum and the cranium [19]. CT scans are also relatively cheap, has a short procedural time and is easily accessible [20].

Although MRI scans have superior anatomic clarity, high soft tissue contrast and less radiation exposure, it is not widely used as an emergency imaging modality for head and neck abscesses compared to CT [20]. This may be due to increased cost, difficult interpretation compared to CT and length of procedure [20]. Ultrasonography can be used to assess head and neck abscesses, but the anatomic detail provided by CT makes it superior in confirming the presence of an abscess [21].

In this case, contrast-enhanced CT was used to identify the spread of pus into deeper spaces and anterior chest wall following initial treatment, and for guiding extensive incision and drainage under general anesthesia to prevent further expansion.

Rapidly spreading deep neck infections will tend to descend into the mediastinum, but involvement of the anterior chest wall secondary to an odontogenic infection is an unusual occurrence. This is the second case in the literature of an anterior chest wall abscess secondary to an odontogenic infection, but the first report of an abscess superficial to the pectoralis major muscle. It must be kept in mind that odontogenic infections have the potential to spread into any anatomical plane, some more than others. Early recognition of potential spread of infection into life threatening areas of the thorax as well as recognizing the potential development of necrotizing fasciitisis vital for a favorable prognosis and good outcome.

\section{References}

1. Moghimi M, Baart JA, Karagozoglu KH, Forouzanfar T. Spread of odontogenic infections: a retrospective analysis and review of the literature. Quintessence Int. 2013; 44: 351-361.

2. Sato FR, Hajala FA, Freire Filho FW, Moreira RW, de Moraes M. Eightyear retrospective study of odontogenic origin infections in a postgraduation program on oral and maxillofacial surgery. J Oral Maxillofac Surg. 2009; 67: 1092-1097.

3. Bridgeman A, Wiesenfeld D, Newland S. Anatomical considerations in the diagnosis and management of acute maxillofacial bacterial infections. Aust Dent J 1996; 41: 238-245

4. Bakir S, Tanriverdi MH, Gun R, Yorgancilar AE, Yildirim M, Tekbas G, et al. Deep neck space infections: a retrospective review of 173 cases. Am J Otolaryngol. 2012; 33: 56-63.

5. Vieira F, Allen SM, Stocks RM, Thompson JW. Deep neck infection. Otolaryngol Clin North Am. 2008; 41: 459-483.

6. Cortese A, Pantaleo G, Borri A, Amato M, Claudio PP. Necrotizing odontogenic fasciitis of head and neck extending to anterior mediastinum in elderly patients: innovative treatment with a review of the literature. Aging Clin Exp Res. 2017; 29: 159-165.

7. Yuvaraj V, Balasubramanianv K. Anterior chest wall abscess-an unusual complication of an odontogenic infection. Oral and Maxillofacial Surgery, 2010; 14: 239-241

8. Eisler L, Wearda K, Romatoski K, Odland RM. Morbidity and Cost of Odontogenic Infections. Otolaryngol Head Neck Surg. 2013; 149: 84-88.

9. Ariji Y, Gotoh M, Kimura Y, Naitoh M, Kurita K, Natsume N, et al. Odontogenic infection pathway to the submandibular space: imaging assessment. Int $J$ Oral Maxillofac Surg. 2002; 31: 165-169.

10. Marioni G, Rinaldi R, Staffieri C, Marchese-Ragona R, Saia G, Stramare R, et al. Deep neck infection with dental origin: analysis of 85 consecutive cases [2000-2006]. Acta Otolaryngol. 2008; 128: 201-206

11. Bakathir AA, Moos KF, Ayoub AF, Bagg J. Factors contributing to the spread of odontogenic infections: A prospective pilot study. Sultan Qaboos Univ Med J. 2009; 9: 296-304.

12. Peterson LJ. Complex odontogenic infections. In: Contemporary Oral and Maxillofacial Surgery. Peterson LJ, Ellis E III, Hupp JR, Tucker M [Eds.]. $4^{\text {th }}$ Edn. Mosby, Missouri. 2013; 418-432. 
13. Chow AW, Roser SM, Brady FA. Orofacial odontogenic infections. Ann Intern Med. 1978; 88: 392-402.

14. Maya SP, Beltrán DD, Lemercier P, Leiva-Salinas C. Necrotizing fasciitis: an urgent diagnosis. Skeletal Radiol. 2014; 43: 577-589.

15. Crew JR, Thibodeaux KT, Speyrer MS, Gauto AR, Shiau T, Pang L, et al Flow-through Instillation of Hypochlorous Acid in the Treatment of Necrotizing Fasciitis. Wounds. 2016; 28: 40-47.

16. Crew JR, Varilla R, Allandale Rocas lii T, Abdul Rani S, Debabov D. Treatment of Acute Necrotizing Fasciitis Using Negative Pressure Wound Therapy and Adjunctive NeutroPhase Irrigation Under the Foam. Wounds. 2013; 25: 272-277

17. Sarani B, Strong M, Pascual J, Schwab CW. Necrotizing fasciitis: curren concepts and review of the literature. J Am Coll Surg. 2009; 208: 279-288.
18. McMahon J, Lowe T, Koppel DA. Necrotizing soft tissue infections of the head and neck: Case reports and literature review. Oral Oral Surg Oral Med Oral Pathol Oral Radiol Endod. 2003; 95: 30-37.

19. Kim YJ, Kim JD, Ryu HI, Cho YH, Kong JH, Ohe JY, et al. Application of radiographic images in diagnosis and treatment of deep neck infections with necrotizing fasciitis: a case report. Imaging Sci Dent. 2011; 4: 189-193.

20. Muñoz A, Castillo M, Melchor MA, Gutiérrez R. Acute neck infections: prospective comparison between $\mathrm{CT}$ and MRI in 47 patients. $\mathrm{J}$ Comput Assist Tomogr. 2001; 25: 733-741.

21. Hilbert G, Vargas F, Valentino R, Gruson D, Chene G, Bébéar C, et al Comparison of B-mode ultrasound and computed tomography in the diagnosis of maxillary sinusitis in mechanically ventilated patients. Crit Care Med. 2001; 29: 1337-1342. 